\title{
FACTORS IN THE EARLY FAILURE OF CRYOPRESERVED HOMOGRAFT PULMONARY VALVES IN CHILDREN: PRESERVED IMMUNOGENICITY?
}

Roger J. Baskett, MA

David B. Ross, MD

Maurice A. Nanton, MB

David A. Murphy, MD
Methods: Between 1990 and 1995, 48 homograft valves (15 aortic and 33 pulmonary), cryopreserved on-site, were implanted to reconstruct the right ventricular outflow tracts in 44 children (mean age $6.2 \pm 6.0$ years; range 3 days to 20.2 years). Blinded serial echocardiographic follow-up evaluation was performed for all 45 valves in the 41 survivors. Results: Four homograft valves were replaced because of pulmonary insufficiency (3) or stenosis and insufficiency (1). Freedom from reoperation was $90 \%$ (70\% interval, $84 \%$ to 97\%) at 50 months. During the follow-up period 15 valves developed progressive pulmonary insufficiency of at least two grades. Three valves developed transvalvular gradients of $\geq 50 \mathrm{~mm} \mathrm{Hg}$, and one of these valves was also insufficient. The freedom from echocardiographic failure (two or more grades of pulmonary regurgitation or $\geq 50 \mathrm{~mm} \mathrm{Hg}$ gradient) was $44 \%$ at 50 months (70\% confidence interval, $32 \%$ to $55 \%)$. Young age ( $p=0.03$ ), low operative weight $(p=0.04)$, small graft size $(p=0.04)$, and homograft retrieval-to-cryopreservation time of less than 24 hours $(p=0.02)$ were significantly associated with failure. The type of donor valve (pulmonic or aortic), donor age, and blood group mismatch were not associated with failure, although blood group mismatch approached significance $(p=$ 0.05). Conclusions: Homografts function well as conduits between the pulmonary ventricle and pulmonary arteries if long-term valve competency is not crucial. However, many rapidly become insufficient. This has important implications for the choice of a valve if the indication for valve replacement is to protect a ventricle failing due to pulmonary insufficiency. Short periods between homograft retrieval and cryopreservation enhance viability and antigenicity. This may suggest an immunologic basis for the failure. (J Thorac Cardiovasc Surg 1996;112:1170-9)
$\mathrm{H}_{\mathrm{c}}$ omograft valves are widely used in the repair of congenital heart anomalies as conduits between the pulmonary ventricle and pulmonary arteries and as valves to protect a ventricle failing due to pulmonary insufficiency and stenosis. The freedom from

From the Department of Cardiovascular Surgery and The Department of Cardiology, IWK Children's Hospital, Dalhousie University, Halifax, Nova Scotia, Canada.

Read at the Seventy-sixth Annual Meeting of The American Association for Thoracic Surgery, San Diego, Calif., April 28-May 1, 1996.

Received for publication May 6, 1996; revisions requested June 12, 1996; revisions received July 3, 1996; accepted for publication July 12, 1996.

Address for reprints: David B. Ross, MD, IWK Children's Hospital, 5850 University Ave., P.O. Box 3070, Halifax, Nova Scotia, Canada. B3J 3G9.

Copyright (C) 1996 by Mosby-Year Book, Inc.

$0022-5223 / 96 \$ 5.00+0 \quad \mathbf{1 2 / 6 / 7 6 5 1 4}$ reoperation rates reported for series of cryopreserved valves for right ventricular outflow tract (RVOT) reconstruction in the young have been $55 \%$ to $80 \%$ at 4 to 6 years. ${ }^{1-4}$ Doubt has been expressed about the durability of homografts in in the aortic and pulmonary positions in children. ${ }^{5-7}$

Adequate homograft function is usually reported in terms of freedom from reoperation, but this is a relatively insensitive measure of valve integrity. Pulmonary insufficiency may be well tolerated if the pulmonary arteries are normal and pulmonary resistance is low. However, many children requiring RVOT reconstruction have abnormal pulmonary vasculature and decreased right ventricular function. Longer follow-up demonstrates that a competent, nonstenotic pulmonary valve is important to preserve ventricular function and optimize exercise capacity. ${ }^{8-10}$

This study was undertaken to examine the inci- 
Table I. Homograft valve patients

\begin{tabular}{lr}
\hline \multicolumn{1}{c}{ Primary diagnosis } & No. \\
\hline Pulmonary atresia or ventricular septal defect & 13 \\
Tetralogy of Fallot & 8 \\
Complex transposition & 8 \\
Truncus arteriosus & 5 \\
Double outlet right ventricle & 4 \\
Pulmonary stenosis/atresia & 3 \\
Aortic stenosis (Ross procedure) & 3 \\
Total & 44 \\
\hline
\end{tabular}

dence, progression, and determinants of cryopreserved homograft valve failure in the RVOTs of children.

\section{Methods}

Patient population. From December 1990 to May 1995 at the IWK Children's Hospital 48 cryopreserved homograft valves (33 pulmonary and 15 aortic) were implanted in 44 patients (22 girls and 22 boys) for reconstruction of the RVOT or pulmonary valve replacement for a variety of congenital lesions (Table I). The mean age at operation was $6.2 \pm 6.0$ years (range 3 days to 20.2 years), and 15 patients were younger than 1 year. Mean weight was $21.0 \pm 18.3 \mathrm{~kg}$ (range 2.8 to $72 \mathrm{~kg}$ ). Forty-one $(85 \%)$ of 48 patients had undergone at least one previous cardiac operation (Table II).

Homograft procurement and preparation. The 48 homograft valves were harvested en bloc with the heart by a surgeon or a tissue bank technologist under sterile conditions from 39 donors; both valves were used from nine donors (Table III).

Donors as old as 65 years were accepted. Standard exclusion criteria included historic or serologic evidence of viral infection (e.g., human immunodeficiency virus, hepatitis B or C), malignancy (except nonmetastatic central nervous system tumors), long-term corticosteroid therapy, or evidence of valvular heart disease or cardiac trauma. The valves were incubated in $500 \mathrm{ml}$ of Hanks balanced salt solution containing $40 \mathrm{mg}$ of gentamicin and $500 \mathrm{mg}$ of cefazolin at $4^{\circ} \mathrm{C}$ for a mean of $31.3 \pm 11.5$ hours (range 12 to 72 hours). Valves were then inspected, trimmed, and measured, and macroscopically defective valves were discarded. Four small tissue biopsy specimens were obtained from each valve for culture of aerobic bacteria, anaerobic bacteria, fungi, and mycobacteria. The valves were then cryopreserved in Hanks balanced salt solution with $10 \%$ dimethylsulfoxide as a cryoprotectant. The valves were cooled in a controlled-rate freezer (Planer KRYO10, Planer Products Ltd., Sunbury-onThames, Middlesex, U.K.) at $1^{\circ} \mathrm{C} /$ minute to a temperature of $-80^{\circ} \mathrm{C}$ and stored in vapor-phase liquid nitrogen below $-135^{\circ} \mathrm{C}$ until used. Valves were transported in a cooler with liquid nitrogen to the operating theater and thawed in a water bath at $39^{\circ} \mathrm{C}$.

Operative technique. All valves were implanted by two surgeons. The operations were performed through a median sternotomy with standard cardiopulmonary techniques and mild hypothermia $\left(32^{\circ} \mathrm{C}\right)$. The aortic root was
Table II. Previous cardiac surgery

\begin{tabular}{lr}
\hline \multicolumn{1}{c}{ Procedure } & No. \\
\hline Modified Blalock-Taussig shunt & 22 \\
Tetralogy of Fallot repair & 13 \\
Pulmonary valve replacement & 8 \\
Central shunt & 6 \\
Aortic valvotomy & 6 \\
Rastelli repair & 5 \\
Arterial switch & 4 \\
RVOT annular patch & 4 \\
Pulmonary valvotomy & 3 \\
VSD repair & 2 \\
Senning & 1 \\
\hline
\end{tabular}

RVOT, Right ventricular outflow tract; VSD, ventricular septal defects. ${ }^{*}$ Three valvotomies were performed in one patient and two in another one.

Table III. Homograft valve characteristics

\begin{tabular}{lccc}
\hline \multicolumn{1}{c}{ Source } & No. & Mean & Range \\
\hline $\begin{array}{l}\text { Heart transplant } \\
\quad \text { recipients }\end{array}$ & 4 & & \\
$\begin{array}{l}\text { Brain-dead multiorgan } \\
\quad \text { donors }\end{array}$ & 11 & & \\
Tissue-only donors & 24 & & \\
Total & 48 & & \\
Age of donor & & $20.3 \pm 16.8 \mathrm{yr}$ & 3 days to $58 \mathrm{yr}$ \\
$\quad$ Valve size & & $17.2 \pm 3.7 \mathrm{~mm}$ & 9 to $25 \mathrm{~mm}$ \\
Ischemic time $\dagger$ & $4.4 \pm 3.7 \mathrm{hr}$ & 1 to $18.5 \mathrm{hr}$ \\
Retrieval-to-preservation & & $31.3 \pm 11.5 \mathrm{hr}$ & 12 to $72 \mathrm{hr}$ \\
$\quad$ time & & & \\
& & &
\end{tabular}

${ }^{*}$ Both valves were used from nine donors.

†Time from heart cessation to valve incubation at $4^{\circ} \mathrm{C}$ in Hanks balanced salt solution and antibiotics.

\$Time from onset of valve incubation to onset of cryopreservation.

not routinely crossclamped unless other procedures, such as ventricular septal defect closure or an aortic autograft procedure, were required. In seven patients the pulmonary reconstruction involved implanting the homograft as a bifurcated graft; the others had circumferential distal anastomosis. Proximal extensions of autologous pericardium or homograft material were added in 22 patients. An additional four patients had proximal extensions of $\mathrm{Da}$ cron polyester fiber. All proximal extensions were placed as patches and none as tubular grafts. Valve size was determined by the surgeon and was always larger than the minimum acceptable pulmonary annulus diameter as determined by Pacifico and colleagues. ${ }^{11}$ Pulmonary valves were used preferentially. No attempt was made to match donor and recipient for blood type.

Echocardiographic evaluation. All surviving patients were examined in the immediate postoperative period and reexamined serially with transthoracic echocardiograms every 6 to 12 months. All studies were reviewed in a random and blinded fashion by one pediatric cardiologist. Pulmonary regurgitation (PR) was assessed by looking at 


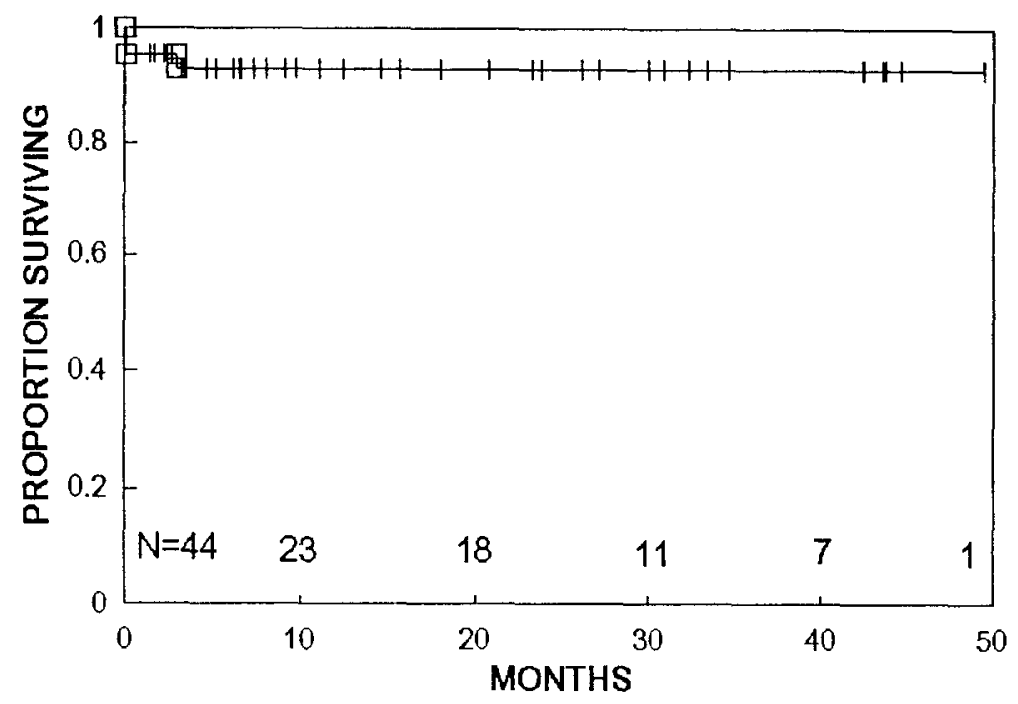

Fig. 1. Actuarial survival of all patients undergoing reconstruction of the right ventricular outflow tract with a cryopreserved homograft.

the regurgitant jet with pulsed color-flow Doppler, particularly its width at the source and how far it entered the corresponding ventricle. The severity was graded semiquantitatively from 0 to $4+$, in a manner similar to that described by Chan and coworkers ${ }^{6}$ : 0 , absent; $1+$, a pinhole jet; $2+$, a jet of regurgitation approximately $20 \%$ of the valve annulus; $3+$, a wide-based jet approximately $40 \%$ of the annular width; $4+$, a broad jet larger than $40 \%$ of the annular width. When possible, observations were made with the short-axis parasternal view. Stenosis was assessed by measuring the peak velocity through the valve with continuous-wave Doppler technique. The highest peak velocity was used in the simplified Bernoulli equation: gradient $=4 \times$ peak velocity ${ }^{2}$.

Statistical analysis. Data are presented as the mean \pm the standard deviation. All statistical tests were conducted with SAS version 6.08 (SAS Institute Inc., Cary, N.C.). ${ }^{12}$ Twelve variables were analyzed in a univariate analysis for significant association with echocardiographic failure. Continuous variables were analyzed with Student's $t$ test and categorical variables using a $\chi^{2}$ test. A forward stepwise discriminant function analysis was also conducted to determine which combination of these variables best predicted valve failure. Variables were chosen to enter the model based on a critical F test $(p<0.05)$ from an analysis of covariance in which the variables already added to the model act as covariates and the variable under consideration is the dependant variable. ${ }^{12}$ The outcome measure of valve failure was defined as a progression of $\geq 2+$ PR or a transvalvar gradient of $\geq 50 \mathrm{~mm}$ $\mathrm{Hg}$. Because of the inherent subjectivity in interpreting echocardiograms, a change of $\geq 2+P R$ or a $\geq 50 \mathrm{~mm} \mathrm{Hg}$ gradient was thought to be significant and is supported in the literature. 6

Life tables for freedom from valve failure, reoperation, or death were calculated using the Blossom statistical program (Blossom, BR Cole, National Institutes of
Health, Bethesda, Md.). Confidence intervals (70\%) were approximated from the standard error for actuarial survival estimates.

\section{Results}

The three early deaths all were patients with complex truncus arteriosus, and there were no late deaths. No patient was lost to follow-up. Actuarial survival was $93 \%$ at 50 months $(70 \%$ confidence interval, $89 \%$ to $97 \%$ ) (Fig. 1).

Four valves $(8.9 \%)$, have been explanted, resulting in an actuarial freedom from reoperation rate of $90 \%$ at 50 months ( $70 \%$ confidence interval, $84 \%$ to 97\%) (Fig. 2). The first homograft was removed 14 months after implantation in an 11-year-old patient with complex tetralogy of Fallot. The valve had become acutely insufficient because of embolization of a clam shell device that had been used to close a ventricular septal defect 5 months. earlier. At reoperation the device was found in the main pulmonary artery. The leaflets of the valve were found to be in good condition, except for a tear. The most recent echocardiogram had shown no regurgitation and no gradient. The new homograft functioned well for 3 months but showed a progressive increase of PR to $4+$ at 22 months after implantation.

The second pulmonary valve reoperation was in a 7-month-old child 5 months after implantation. This patient with tetralogy of Fallot and pulmonary atresia developed an RVOT aneurysm, pulmonary regurgitation, and right ventricular failure. At reop- 


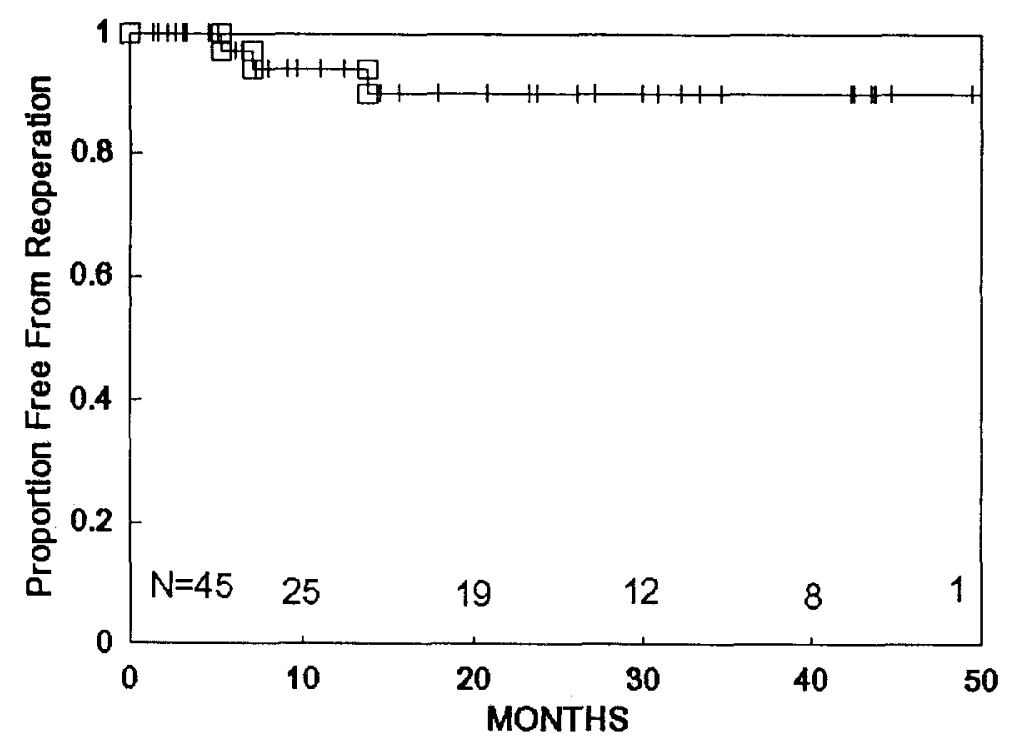

Fig. 2. Actuarial freedom from reoperation in the 41 survivors.

eration there was no evidence of the valve tissue. The replacement homograft was functioning well, with trivial regurgitation and a moderate gradient of $40 \mathrm{~mm} \mathrm{Hg}$ seen at the last echocardiogram 2 years later.

A third child, also with tetralogy of Fallot and pulmonary atresia, had a homograft implanted when he was 2 years 9 months old because of continued right ventricular failure after tetralogy repair. This child developed $2+$ PR within 5 months of the operation. He remained well clinically, but the regurgitation continued to increase and was $4+2$ years after the operation. The homograft also became progressively obstructive; the initial gradient was $24 \mathrm{~mm} \mathrm{Hg}$, and it had progressed to $90 \mathrm{~mm} \mathrm{Hg}$ at the time of reoperation. At reoperation 4 years after implantation, the leaflets were still present but furled together. Immediately after the operation the replacement homograft had a $1+$ PR grade and a transvalvular gradient of $<20 \mathrm{~mm} \mathrm{Hg}$. Four months later there is no change on echocardiography, and the child is without symptoms.

The fourth child also suffered from tetralogy of Fallot with pulmonary atresia. The first homograft was inserted in the 11-month-old child because of congestive failure due to high pulmonary artery pressures. The valve developed $2+\mathrm{PR}$ within 2 months, and 7 months after it was implanted, the homograft was replaced because of worsening congestive failure. The new homograft also rapidly developed $2+$ PR. The patient's condition is stable, but the patient has limited exercise tolerance and remains in right-sided heart failure.

Postoperative echocardiograms were obtained in all 45 valves in the 41 survivors at a mean of $9.8 \pm$ 9.5 days (range 1 to 41 days) after repair. The mean follow-up time was $20.6 \pm 15.8$ months (range 3 to 52 months). For four patients the echocardiographic windows were inadequate to allow comment on valve function; the echocardiographic follow-up is therefore for $41(91 \%)$ of 45 valves. Three of the patients had initial postoperative echocardiograms showing $2+$ or $3+$ PR and were excluded from the statistical analysis because they were considered technical failures. Figure 3 shows the extent of pulmonary regurgitation at the last echocardiogram. Only three valves had a gradient of $\geq 50 \mathrm{~mm} \mathrm{Hg}$, (Fig. 4) one of these also had 4+ PR. The other two had no PR.

Seventeen $(45 \%)$ of 38 of the valves failed (15 with $\geq 2+$ PR grades, two with $\geq 50 \mathrm{~mm} \mathrm{Hg}$ gradients, and one with both). Actuarial freedom from failure was $44 \%$ at 26 and 50 months (70\% confidence interval, $32 \%$ to $55 \%$ ) (Fig. 5). The mean time to failure was $8.9 \pm 6.9$ months (range 1 to 26 months).

The univariate analysis showed that young age at operation, low weight, small graft size, and a time for homograft retrieval to cryopreservation of less than 24 hours were significantly associated with the development of $\geq 2+$ PR or a $\geq 50 \mathrm{~mm} \mathrm{Hg}$ transvalvular gradient. None of the other variables was 


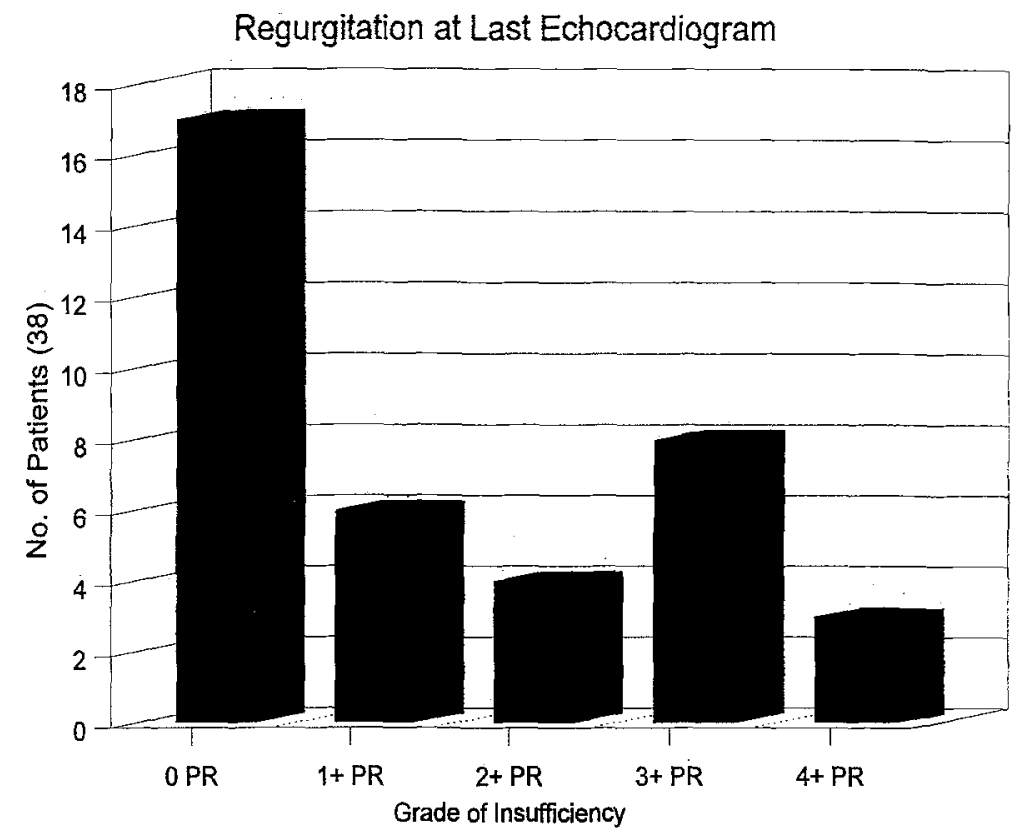

Fig. 3. Pulmonary insufficiency (PR) assessed by pulsed color-flow Doppler echocardiography for 38 patients.

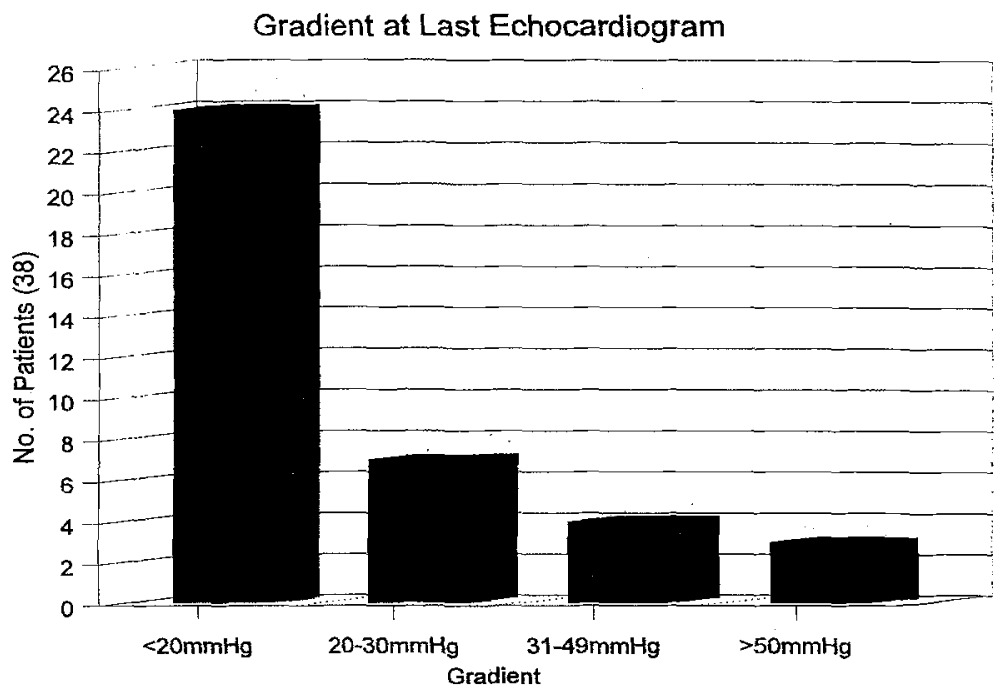

Fig. 4. Transvalvular gradient measured by peak velocity (PV) at the valve with continuous-wave Doppler echocardiography in 38 patients. The Bernoulli equation (gradient $=4 \times \mathrm{PV}^{2}$ ) was used for the calculations.

found to be statistically significantly associated with failure, although blood group mismatch approached significance (Table IV). The multivariate analysis showed that retrieval-to-cryopreservation time of less than 24 hours, blood group mismatch, and small valve size together predicted $84 \%$ of the failures. The partial correlation coefficients for each of these variables were approximately equal (Table V). These three variables are equally important predictors of failure. Weight and age at operation, significant in the univariate analysis, were not significant predictors of failure in the stepwise discriminant function analysis. They were associated with valve size, and when valve size was controlled for in the 


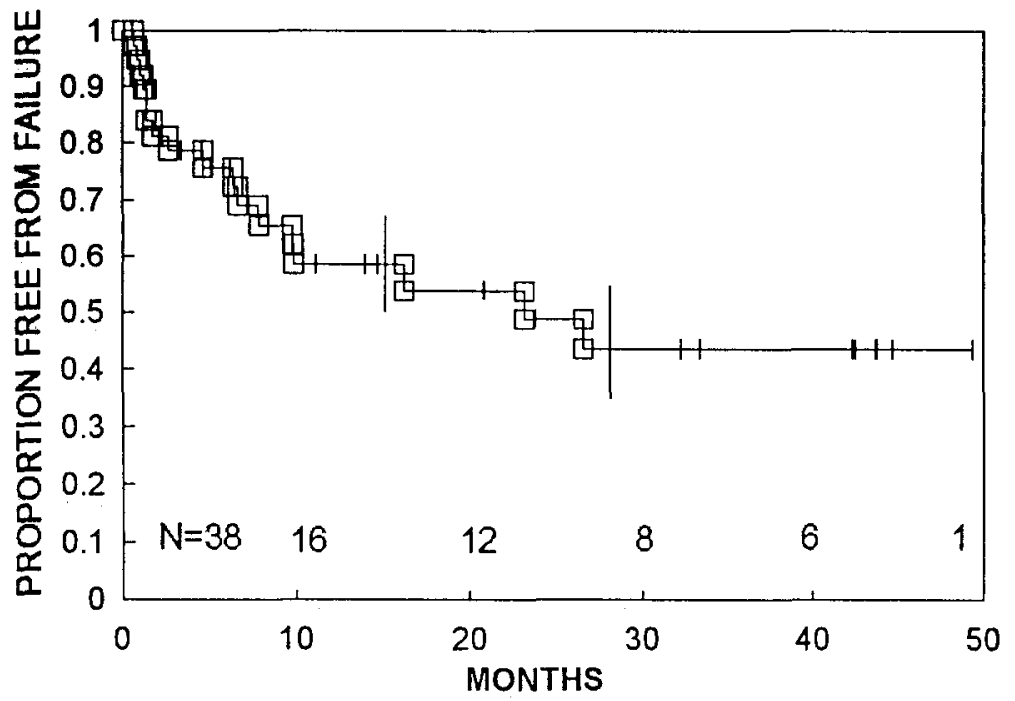

Fig. 5. Actuarial freedom from failure (progression of two or more grades of insufficiency or $\geq 50 \mathrm{~mm} \mathrm{Hg}$ gradient) for the 38 valves analyzed.

multivariate analysis, age and weight became insignificant.

\section{Discussion}

All the patients requiring reoperation had tetralogy of Fallot with significant distal pulmonary artery stenosis. In each case when the valve became incompetent and ceased to protect the ventricle, heart failure developed, leading to reoperation. It is these patients in whom the homograft is most needed as a competent valve rather than a mere conduit. Longstanding PR is associated with decreased exercise tolerance and right ventricular dysfunction after repair of tetralogy. ${ }^{8,9}$ Pulmonary insufficiency after RVOT reconstruction is no longer thought to be innocuous. ${ }^{13}$ The low reoperation rate (see Fig. 2) is in keeping with that reported in other series, but it masks the true incidence of valve failure. ${ }^{1,14}$

Although somewhat subjective, echocardiography provides a more sensitive measure of valve function than freedom from reoperation rates. Echocardiography has been shown to be a reliable method of assessing homograft function. ${ }^{6,15}$

Several factors have been associated with homograft failure when reoperation was used as the outcome measure: young age, ${ }^{1,5-7}$ small valve size, ${ }^{1,7}$ and the use of aortic valves in the RVOT in some series, ${ }^{2,7}$ but not in others. ${ }^{1,6}$ Our results confirm young age and small graft size but not valve type. However, on the basis of the results reported by others, we preferentially used pulmonary valves when possible. ${ }^{2,7}$ How the various factors in valve preparation affect valve longevity has not been fully determined.

It has been suggested that homograft valve failure may result from immunologic rejection, which may be heightened in young children, ${ }^{5,7,16}$ and immunosuppression has been suggested by some research. ${ }^{5,17,18}$ Much of the work with cryopreservation has emphasized the maintenance of viability, based on the belief that the durability of homograft valves is related to the viability of fibroblasts, which maintain the valve matrix. ${ }^{19,20}$ Homograft valve viability is determined by the time between donor heart cessation and harvest and by the preservation technique. ${ }^{19,21}$ Cryopreserved valves are thought to retain viability, but they also retain their immunogenicity. ${ }^{18,22-24}$ Viability and immunogenicity decline as the duration of wet storage at $4^{\circ} \mathrm{C}$ increases. ${ }^{24-26}$ The length of time the valve is sterilized before freezing (i.e., retrieval-to-preservation time) is thought to be an important determinant of immunogenicity. There may be a trade-off between retained structural integrity and retained immunogenicity, both of which are preserved by cryopreservation.

Viable endothelial cells are thought to provide the strongest antigenicity. ${ }^{24,27,28}$ Endothelial cells are the most susceptible to ischemic damage and, when stored in antibiotic solution, are nonviable after 24 hours to 14 days, depending on the type of donor and the length of ischemic time before processing. ${ }^{7,25,27}$ Lang and associates demonstrated 
Table IV. Results of statistical analysis

\begin{tabular}{lll}
\hline \multicolumn{1}{c}{ Variables } & $p$ Value & Test used \\
\hline Continuous & & \\
$\quad$ Young age at operation & 0.03 & Student $t$ test \\
Low weight at operation & 0.04 & Student $t$ test \\
Small graft size & 0.04 & Student $t$ test \\
$\quad$ Donor age & 0.32 & Student $t$ test \\
$\quad$ Valve ischemic time $\dagger$ & 0.76 & Student $t$ test \\
Categorical & & \\
$\quad$ Retrieval to preservation time & 0.02 & $\chi^{2}$ \\
$\quad<24$ or >24 hrł & & \\
$\quad$ Graft type (pulmonic or aortic) & 0.58 & $\chi^{2}$ \\
$\quad$ Graft or host size mismatch $\$$ & 0.58 & $\chi^{2}$ \\
Blood group mismatch & 0.05 & $\chi^{2}$ \\
$\quad$ Previous cardiac surgery & 0.88 & $\chi^{2}$ \\
$\quad$ Donor type (organ or tissue) & 0.44 & $\chi^{2}$ \\
$\quad$ Use of Dacron & 0.68 & $\chi^{2}$ \\
\hline
\end{tabular}

*Rounded off to two decimal places.

tTime from heart cessation to valve incubation at $4^{\circ} \mathrm{C}$ in antibiotic and Hank's balanced salt solution.

¥Time from onset of valve incubation to onset of cryopreservation.

$\S$ Valve size $>95$ th percentile for the patient's weight as described by Pacifico, Kirklin, and Blackstone. ${ }^{11}$

that, after 12 to 24 hours of storage at $4^{\circ} \mathrm{C}$ before cryopreservation, endothelial cells of the homografts retained the capacity to proliferate, but those stored for 3 weeks at $4^{\circ} \mathrm{C}$ did not. ${ }^{29}$ Although homograft immunogenicity has been demonstrated to be retained despite the attenuation of endothelial viability ${ }^{24}$ it is apparent that the precise nature of homograft valve viability and immunogenicity is not understood.

Five valves in our series had retrieval-to-preservation times of less than 24 hours. Four of the 17 valves that failed had retrieval-to-preservation times of less than 24 hours, and none of the competent valves had a time less than 24 hours. The fifth valve had an initial postoperative echocardiogram showing a $2+$ insufficiency and was thus excluded from the analysis, although at the most recent echocardiogram it was judged to have $3+$ insufficiency. Valves with short retrieval-to-preservation times $(<24$ hours) were significantly more likely to fail $(p=0.02)$.

Blood group incompatibility approached significance in the current series $(p=0.05)$ and was a significant predictor of failure in the multivariate analysis (see Table V). The significance of blood group incompatibility has long been postulated and its importance suggested by some, ${ }^{30}$ although other studies have failed to demonstrate this. ${ }^{31,32}$ However, ABO matching has often been carried out to
Table V. Results of stepwise discriminant function analysis

\begin{tabular}{lccc}
\hline \multicolumn{1}{c}{ Variable $^{*}$} & Partial $^{2}$ & F statistic & $p$ Value \\
\hline Retrieval to preservation time & 0.145 & 6.121 & 0.018 \\
$\quad<24$ hours & & & \\
Graft size & 0.143 & 5.857 & 0.020 \\
Blood group mismatch & 0.157 & 6.361 & 0.017 \\
\hline
\end{tabular}

*These three variables together predicted $84 \%$ of the failures.

some extent, $, 5,27,33$ and it is recommended by several investigators. ${ }^{24,27}$ Homograft ischemic time was not shown to be a significant factor in valve failure in our series $(p=0.76)$, although the ischemic times were all quite short and relatively consistent (Table IV).

Results from earlier work with stored antibioticsterilized valves (i.e., fresh valves) appear to be at least as good and perhaps better than those achieved with the cryopreserved valves, particularly considering the longer follow-up. ${ }^{33-36}$ This may be the result of decreased antigenicity, which has been demonstrated in homografts stored for several weeks. ${ }^{24,27}$ However, the great variability in patient selection, age, surgical technique, perioperative mortality, procurement and preservation techniques, and follow-up make a valid comparison impossible. ${ }^{37}$ Our experience and that of others with cryopreserved homograft degeneration in young children has emphasized the need to further investigate the cause and mechanism of this early failure. $^{5,6,16}$

Factors other than rejection and growth must be considered in assessing the mechanisms of homograft valve failure. ${ }^{14}$ Geometric distortion has been recognized as a factor in aortic homograft replacement and is largely responsible for the switch from a subcoronary insertion to root replacement. This may be a factor in the pulmonary position as well. However, all the valves in our study were implanted as intact cylinders. Christie and BarrattBoyes demonstrated that the loss of valve leaflet extensibility over time leads to increasing valve incompetence. ${ }^{38}$. This could explain long-term failure, and the effect may result from decreased viability, immunologic rejection, or a combination of the two in conjunction with subtle geometric distortion. Although immunologic factors do not fully explain valve failure, they cannot be ignored as a factor in early homograft valve failure, particularly in young children. 


\section{Conclusions}

The cryopreserved homograft is effective as a conduit between the pulmonary ventricle and the pulmonary arteries. However, the early development of significant incompetence limits its usefulness for protecting the ventricle from high pulmonary artery pressures when a competent valve is essential. Dysfunction of the valves is common and progressive over the first 6 to 12 months (see Fig. 5). This early failure is more in keeping with rejection than the inevitible tissue degeneration seen in late failure. ${ }^{38}$ Small graft size was a significant factor in valve failure, but a valve larger than the 95th percentile for weight was not. ${ }^{11}$ The practice of oversizing valves to allow for growth appears to be justified..$^{38}$ We found no difference in aortic versus pulmonary valves $(p=0.58)$, although pulmonary valves were used whenever possible; 33 pulmonary and 15 aortic valves were used.

Our finding of short retrieval-to-preservation time and blood group incompatibility as significantly associated with homograft valve failure lends some clinical support to the suggested immunologic nature of early homograft failure in children. Although some surgeons have used a variety of immunosuppressive regimens on small numbers of patients, the current state of knowledge does not seem to support this as a routine practice. ${ }^{16,32,39}$

Continued work is required to assess the significance of the immune response to cryopreserved homograft valves. Some studies have shown an immune response to valves in the laboratory. ${ }^{22-24}$ The nature of this response needs to be characterized and methods to modify it should be assessed, initially in the laboratory and then clinically. Because of the small number of patients operated on at any single institution and the great variability in such a heterogenous group of patients, multicentered randomized studies will be necessary to assess the efficacy of any clinical intervention. Interventions aimed at modifying the immunogenicity of the donor valve and the recipients response appear to be indicated.

We thank Christopher T. Naugler, MSc, Faculty of Medicine, Dalhousie University, for help with the statistical analysis and acknowledge the assistance of Andre LaPrairie and the staff of the Victoria General Hospital Regional Tissue Bank.

\section{REFERENCES}

1. Hawkins JA, Bailey WW, Dillon T, Schwartz DC. Midterm results with cryopreserved allograft valved conduits from the right ventricle to the pulmonary arteries. $\mathbf{J}$ Thorac Cardiovase Surg 1992;104:910-6.

2. Cleveland DC, Razzouk RJ, Williams WG, et al. Homograft valved conduit failure in the pulmonary circulation. Can J Cardiol 1991;7 Suppl A:286.

3. Salim MA, DiSessa TG, Alpert BS, et al. The fate of homograft conduits in children with congenital heart disease: an angiographic study. Ann Thorac Surg 1995;59:67-73.

4. Lamberti JJ, Mainwaring RD, Billman GF, et al. The cryopreserved homograft valve in the pulmonary position: midterm results and technical considerations. J Card Surg 1991; 6(4 Suppl):627-32.

5. Clarke DR, Campbell DN, Hayward AR, Bishop DA. Degeneration of aortic valve allografts in young recipients. $\mathrm{J}$ Thorac Cardiovasc Surg 1993;105:934-42.

6. Chan KC, Fyfe DA, McKay CA, Sade RM, Crawford FA. Right ventricular outflow reconstruction with cryopreserved homografts in paediatric patients: intermediate-term follow-up with serial echocardiographic assessment. J Am Coll Cardiol 1994;24:483-9.

7. Bando K, Danielson GK, Schaff HV, et al. Outcome of pulmonary and aortic homografts for right ventricular outflow tract reconstruction. J Thorac Cardiovase Surg 1995;109: 509-18.

8. Bove EL, Byrum CJ, Thomas FD, et al. The influence of pulmonary insufficiency on ventricular function following repair of tetralogy of Fallot. J Thorac Cardiovasc Surg 1983;85:691-6.

9. Meijboom F, Szatmari A, Deckers JW, et al. Cardiac status and health-related quality of life in the long term after surgical repair of tetralogy of Fallot in infancy and childhood. J Thorac Cardiovasc Surg 1995;110:883-91.

10. Rowe SA, Zahka KG, Manolio TA, Horneffer PJ, Kidd L. Lung function and pulmonary regurgitation limit exercise capacity in postoperative tetralogy of Fallot. J Am Coll Cardiol 1991;17:461-6.

11. Pacifico AD, Kirklin JW, Blackstone EH. Surgical management of pulmonary stenosis in tetralogy of Fallot. J Thorac Cardiovase Surg 1977;74:382-95.

12. SAS Institute Inc. SAS/SAT user's guide. 6.03 edition. Cary, NC: SAS Institute, 1988.

13. Hopkins RA. Right ventricular outflow tract reconstructions: the role of valves in the viable allograft era. Ann Thorac Surg 1988;45:593-4.

14. McGiffin DC. Leaflet viablity and the duribility of the allograft aortic valve [invited letter]. J Thorac Cardiovasc Surg 1994;108:988-90.

15. Meliones JN, Snider AR, Bove EL, et al. Doppler evaluation. of homograft valved conduits in children. Am J Cardiol 1989;64:354-8.

16. Ross DN. Evolution of the homograft valve. Ann Thorac Surg 1995;59:565-7.

17. Gonzalez-Lavin L, Bianchi J, Graf D, Amini S, Gordon CI. Homograft valve calcification: evidence for an immunological influence. In: Yankah AC, Hetxer R, Miller DC, Ross DN, Somerville J, Yacoub MH, editors. Cardiac valve allografts 1962-87. New York: Springer-Verlag, 1988:69-74.

18. Ross DN: Discussion of Clarke DR, Campbell DN, Hayward $R$, Bishop DA. Degeneration of aortic valve allografts in young recipients. J Thorac Cardiovasc Surg 1993;105:934-42.

19. Heacox AE, McNally RT, Brockbank KGM. Factors affecting the viability of cryopreserved allograft heart valves. In: 
Yankah AC, Hetxer R, Miller DC, Ross DN, Somerville J, Yacoub MH, editors. Cardiac valve allografts 1962-87. New York: Springer-Verlag, 1988:37-42.

20. O'Brien MF, Stafford EG, Gardner MAH, Pohlner PG, McGiffin DC. A comparison of aortic valve replacement with viable cryopreserved and fresh allograft valves, with a note on chromosomal studies. J Thorac Cardiovasc Surg 1987;94:81223.

21. Crescenzo DG, Hilbert SL, Messier RH, et al. Human cryopreserved homografts: electron microscopic analysis of cellular injury. Ann Thorac Surg 1993;55:25-31.

22. El Khatib H, Lupinetti FM. Antigenicity of fresh and cryopreserved rat valve allografts. Transplantation 1990;49:76567.

23. Cochran RP, Kunzelman KS. Cryopreservation does no alter antigenic expression of aortic allografts. J Surg Res 1989;46: 597-9.

24. Lupinetti FM, Christy JP, King DM, El Khatib H, Thompson SA. Immunogenicity, antigenicity, and endothelial viability of aortic valves preserved at $4^{\circ} \mathrm{C}$ in a nutrient medium. J Cardiol Surg 1991;6:454-61.

25. Fischlein T, Schutz A, Uhlig A, et al. Integrity and viability of homograft valves. Eur J Cardiothorac Surg 1994;8:425-30.

26. Kumper A, Kumper C, Kraatz EG, et al. Assessment of different preservation and storage conditions on aortic valves: introduction of a qualitative measuring method of the integrity of endothelial cells. Thorac Cardiovase Surg 1989;37: 294-8.

27. Yankah AC, Wottge HU, Muller-Hermelink HK, et al. Transplantation of aortic and pulmonary allografts, enhanced viability of endothelial cells by cyopreservation, importance of histocompatibility. J Card Surg 1987;1 Suppl:20920.

28. Lupinetti FM, Tsai TT, Kneebone JM, Bove EL. Effect of cryopreservation on the presence of endothelial cells on human valve allografts. J Thorac Cardiovasc Surg 1993;106: 912-7.

29. Lang SJ, Giordano MS, Cardon-Cardo C, Summers BD, Staiano-Coico L, Hajjar DP. Biochemical and cellular characterization of cardiac valve tissue after cryopreservation or antibiotic preservation. J Thorac Cardiovasc Surg 1994;108: 63-7.

30. Muller-Hermeling HK, Yankah AC. Immunohistopahtology of cardiac valve allograf explants. In: Yankah AC, Hetxer R, Miller DC, Ross DN, Somerville J, Yacoub MH, editors. Cardiac valve allografts 1962-87. New York: Springer-Verlag, 1988:89-94.

31. Shaddy RE, Tani LY, Sturtevant JE, Lambert LM, McGough EC. Effects of homograft blood type and anatomic type on stenosis, regurgitation and calcium in homografts in the pulmonary position. Am J Cardiol 1992;60:392-3.

32. Yacoub MH. Applications and limitations of histocompatibility in clinical cardiac valve allograft surgery. In: Yankah AC, Hetxer R, Miller DC, Ross DN, Somerville J, Yacoub $\mathrm{MH}$, editors. Cardiac valve allografts 1962-87. New York: Springer-Verlag, 1988:95-102.

33. Radley-Smith, Fagan A, Yacoub M. An eleven year experience of fresh aortic homograft replacement in children. Am J Cardiol 1982;49:1035.

34. Kay PH, Ross DN. Fifteen years' experience with the aortic homograft: the conduit of choice for right ventricular outflow tract reconstruction. Ann Thorac Surg 1985;40:360-3.
35. Shabbo FP, Wain WN, Ross DN. Right venticular reconstruction with aortic homograft conduit: analysis of the long-term results. Thorac Cardiovasc Surg 1980;28:21-5.

36. diCarlo D, de Leval MR, Stark J. Fresh, antibiotic sterilized aortic homografts in extracardiac valved conduits. long-term results. Thorac Cardiovasc Surgeon 1984;32:10-4.

37. Grunkemeier GL, Bodnar E. comparison of structural valve failure among different models of homograft valves. J Heart Valve Dis 1994;3:556-60.

38. Christie GW, Barratt-Boyes BG. Identification of a failure mode of the antibiotic sterilized aortic allograft after 10 years: implications for their long-term survival. J Card Surg 1991;6:462-7.

39. Gallo R, Kumar N, Prabhakar G, Al-Halees Z, Duran CMG. Untitled [letter]. J Thorac Cardiovasc Surg 1994;107:1164.

\section{Discussion}

Dr. Richard A. Hopkins (Washington, D.C.). I thank the Association for the opportunity to comment on this paper and the authors for providing me a copy of the manuscript before this meeting. I think this is an extremely important paper. I agree with the authors' premise for doing the study, and I agree with their conclusions. I think it is a very important biologic and clinical experiment, which sheds tremendous light on the biology of cryopreserved homografts.

I and my colleagues have had experience with about 200 homograft implants; the last 100 have been monitored, as your implants were, with every-6-month echo studies. Our results parallel your findings in terms of survival. However, we have only had two patients who required replacement for homograft failure in the right-sided position and only three others who developed increasing right ventricular pressures or high-grade insufficiency which ultimately required replacement. We had little difficulty with progressive or late regurgitation in the right ventricular outflow tract position. We had a freedom from structural failure rate of about $91 \%$, as opposed to your $44 \%$. Our replacement valves were assessed at 5.5 years, or 2000 days, and your valves were evaluated at about 1500 days. I think it could be illuminating to understand the differences in these two series, because the comparison could give us a clue about what to avoid in the future.

Your results confirm that young age and small graft size are risk factors, and we agree with this but not with whether the aortic or pulmonary valve is used. It is interesting that your failures seem to be in other than the truncus series, which means that the neonates do not seem to be a problem in your series. We agree with that finding, but it is at variance with other studies, and I would like you to comment on the neonatal issue.

Your finding that short retrieval-to-preservation times correlated with failure is the central and most important finding of your study. It supports our own contention that cryopreservation should be good but not too good. Your cold ischemic time after harvest but before the start of incubation in Hanks solution may be the key to this study. What fluid did you place these homografts in for the $4^{\circ} \mathrm{C}$ storage time? In other institutions where the processing is done off-site, storage is most often done in lactated Ringer's solution, which is our preference, because it effectively kills the endothelium. 
We think the geometric factors are important ones and that the reconstruction must be performed to reduce hydraulic turbulence. We agree with your conclusion that oversizing is good as long as it does not lead to distortion. However, the proximal reconstruction is very important. Did you use polytetrafluoroethylene (PTFE)* hoods to smooth the fluid flow entry architecture into the conduit to optimize hydraulics and avoid turbulence just below the valve leaflets? Did you avoid distal Dacron graft extensions?

Were you able to examine your explanted valve leaflets for the presence of inflammatory cells, macrophages, fibrous sheathing, and most importantly, to look for preservation of donor matrix or endothelial cells? Have you been able to compare those with your homografts after the preservation techniques and before implantation as a comparison of the cell biology at the time of implantation?

I think this is a superb and critically important study. I applaud the authors for accomplishing it and the Association for selecting it for presentation. I greatly appreciate the opportunity to have discussed its contents.

Dr. Baskett. Thank you very much, Dr. Hopkins. Regarding the neonatal issue, we did not look specifically at the diagnosis; we looked at age as a continuous variable. Because it is quite a heterogeneous group and there are only 44 patients, we did not elect to look at the specific diagnosis because we we would not have the statistical power to say anything about that subject.

With regard to the ischemic times, I welcome your comment that part of the problem may be that our valves are preserved too well with these very short ischemic times. When the valves are explanted, they are placed in Hanks balanced salt solution and then taken to the tissue bank, where they are stored at $4^{\circ} \mathrm{C}$ in Hanks balanced salt solution with the antibiotics that $\mathrm{I}$ listed.

We did not use PTFE in the reconstruction of the outflow tract. In most cases we used proximal extensions of autologous pericardium. In four of the older patients Dacron was used. Two of the valves with Dacron failed, and two of them did not, which was not a significant finding.

With regard to the explanted valves, the four valves that were removed were taken out 6 months to 2 years later. By the time they were removed, they were completely acellular. A pathologist reviewed the H\&E stained slides of these valves and said there was nothing left to look at. Unfortunately, with a retrospective study you are not able to look at the explants.

However, we have established a rat model in our transplantation laboratory to look at what immunologic factors may be involved in the failure of the homografts. Perhaps if I could just show another slide?

\footnotetext{
*Gore-Tex hoods, registered trademark of W. L. Gore \& Associates, Inc., Newark, Del.
}

(Slide) This is a section taken from an explanted valve that was implanted in the abdominal aorta of a rat. This is a syngenic graft at 8 weeks after implantation; and as you can see, there is some intimal thickening, but the valve leaflet itself looks quite normal.

(Slide) This slide is taken from a partially outbred rat and is partially allogeneic. At 4 weeks after implantation the valve leaflets are quite edematous and filled with a mononuclear type infiltrate.

These are some of the preliminary things that we are working on to qualify the immune response.

Dr. Patrick G. Hogan (Brisbane, Queensland, Australia). We are also interested in laboratory aspects of the immune response in a rat model and in human studies. The big problem is establishing the link between the data we have available for humans and whether the valve is actually damaged. Have you seen, given that you have got retrospective echocardiographic data, any suggestion of nodularity or thickening of the valve? If not, do you think that is something that could be looked for in the future?

Dr. Baskett. Thank you, Dr. Hogan. In the early echocardiograms that we reviewed (we had an initial postoperative one for each patient, usually within a week of his or her operation), the valves, except those we excluded, looked very good. As we monitored them, we could see an increase of insufficiency or transvalvular gradient, but we could not see any leaflet abnormalities at all. It is a very good point. Thank you.

Dr. Flavian M. Lupinetti (Seattle, Wash.). I would like to clarify some of our previous work that showed that various neglectful methods of preservation could reduce but not abolish immunogenicity. It seems that the valve can run but it cannot hide. I notice that in your analysis three of the four factors related with failure-young age, small size, and small graft-were perhaps really the same factor, and perhaps an analysis of covariance would have shown that only one of those was truly related to valve failure.

I wonder if there was also a difference in the duration of ischemia in the smaller valve such that an analysis of covariance or a multivariate analysis may have eliminated the ischemic time as a factor leading to valve degeneration?

Dr. Baskett. Thank you, Dr. Lupinetti. We did perform a multivariate analysis, and with your permission, I will show it. We performed a forward stepwise discriminate function analysis for the variables I listed. As Dr. Lupinetti mentioned, the age, graft size, and weight of the patient are related. When you run these factors in a multivariate analysis, graft size comes out as the most significant of the three; when you control for it, the other two drop out. The three variables-retrieval-to-preservation time less than 24 hours, small graft size, and blood type mismatch - were all significant in the multivariate analysis. Ischemic time was not. 